\title{
Strategies to increase limited donor resources
}

\author{
M. de Perrot*, W. Weder", G.A. Patterson", S. Keshavjee*
}

Strategies to increase limited donor resources. M. de Perrot, W. Weder, G.A. Patterson, S. Keshavjee. C ERS Journals Ltd 2004.

ABSTRACT: A number of strategies have been advocated to increase the number of lung donors including: 1) improvement in donor resuscitation; 2) better methods of lung preservation; 3) extension of the lung donor selection criteria; 4) development of a living-related lung donor programme; and 5) utilisation of nonheart beating donors.

Other strategies such as the split-lung technique and techniques of lung reduction to accommodate large lungs into a small-size recipient have also been used successfully. In this article, each of these strategies have been reviewed and some recommendations are suggested based on the authors' ${ }^{\prime}$ own experience and that of the literature. Eur Respir J 2004; 23: 477-482.
*Toronto Lung Transplant Programme, Toronto General Hospital, Toronto, Canada. ${ }^{\#}$ Division of Thoracic Surgery, University Hospital, Zurich, Switzerland. Division of Cardiothoracic Surgery, Washington University School of Medicine, St Louis, MO, USA.

Correspondence: S. Keshavjee, Toronto General Hospital, 200 Elizabeth Street, EN 10-224, Toronto, ON M5G 2C4, Canada.

Fax: 14163404556

E-mail: shaf.keshavjee@uhn.on.ca

Keywords: Donor, graft failure, lung, preservation, reperfusion injury, transplantation

Received: August 172003

Accepted: August 202003
Lung transplantation (LTx) has enjoyed increasing success and has become the mainstay of therapy for selected patients with end-stage lung and pulmonary vascular diseases. Over the past $10 \mathrm{yrs}$, the number of recipients on the waiting list has progressively increased and now far exceeds the number of organs available [1]. Consequently, the median waiting time for LTx has nearly doubled in the USA, and some centres in Europe have reported that up to $50 \%$ of patients awaiting LTx die on the waiting list [2].

\section{Donor resuscitation}

Brain death is associated with a number of events that may complicate the management of multiple organ donors and lead to progressive organ deterioration. This deterioration limits the number of organs available for transplantation and may contribute to the postoperative morbidity and mortality associated with organ transplantation. Mechanisms contributing to organ deterioration include haemodynamic instability, endocrine failure, the inflammatory response, arrhythmias, hypothermia and coagulopathy. Better and more attentive management of donors after brain-death declaration has helped to optimise organ recovery and to increase the number of donors available for LTx.

\section{Haemodynamic management}

The management of multiorgan donors is often a haemodynamic challenge. Hypotension commonly occurs before or soon after brain-death declaration. Causes of hypotension are multiple and include damage to the vasomotor centre, hypovolaemia, left heart dysfunction and endocrine failure. The importance of donor blood pressure on graft function has been clearly demonstrated in the liver and kidney transplant population with an increased incidence of allograft failure and acute tubular necrosis after transplantation when the donor systolic blood pressure was persistently $<80-90 \mathrm{mmHg}[3,4]$.

The goal of haemodynamic management is to maintain adequate circulating blood volume, proper cardiac output, and good perfusion pressure to assure optimal oxygen delivery to organ tissues. Fluid resuscitation is usually considered the first step in the correction of hypotension. However, the goal is to achieve euvolaemia and not hypervolaemia. The central venous pressure (CVP) should be used as a guide to achieve adequate fluid replacement. Optimal filling pressures have not been analysed in human after brain-death declaration. However, experiments with brain-dead pigs have shown that the heart dilates rapidly and fails with a CVP of $>9 \mathrm{mmHg}$ [5]. A CVP of $<10 \mathrm{mmHg}$ is recommended in clinical practice. However, fluid resuscitation must be used cautiously in braindead donors because excessive fluid administration can cause heart dysfunction and rapid deterioration in lung function, even if the CVP remains $<10 \mathrm{mmHg}[6,7]$.

Although the CVP is usually similar to the pulmonary capillary wedge pressure $(P \mathrm{pcw})$, occasionally the CVP and the $P$ pcw may be discordant and the CVP may remain low despite high $P$ pcw due to isolated left heart dysfunction [6]. Hence, if the echocardiography shows left ventricular

Previous articles in this series: No. 1: Glanville AR, Estenne M. Indications, patient selection and timing of referral for lung transplantation. Eur Respir J 2003; 22: 845-852. No. 2: Boehler A, Estenne M. Post-transplant bronchiolitis obliterans. Eur Respir J 2003; 22: 1007-1018. No. 3: Knoop C, Haverich A, Fischer S. Immunosuppressive therapy after human lung transplantation. Eur Respir J 2003; 23: 159-171. No. 4: Kotloff RM, Ahya VN. Medical complications of lung transplantation. Eur Respir J 2003; 23: 334-342. 
dysfunction (ejection fraction $<45 \%$ ), a pulmonary artery catheter should be inserted to facilitate optimisation of cardiac resuscitation [8].

If the blood pressure remains low after adequate fluid resuscitation, vasopressors should be started. Dopamine is used as a first choice with a dose limited to $10 \mu \mathrm{g} \cdot \mathrm{kg}^{-1} \cdot \mathrm{min}^{-1}$ because of its potential vasodilatative effect on renal and mesenteric blood flow. In addition, low-dose dopamine has recently been shown to improve lung oedema in brain-dead donors [9]. Adrenaline and noradrenaline should be tapered off in favour of vasopressin. Vasopressin has been shown to have a stabilising effect on systemic blood pressure after brain death, and to allow reduction or discontinuation of adrenaline and noradrenaline in most cadaveric donors [10-13]. In addition, vasopressin improves maintenance of energy metabolism and is effective against diabetes insipidus, which occurs in $80 \%$ of brain-dead donors [14, 15]. Vasopressin is commonly administered as a bolus (e.g. 5 units) followed by an infusion of $1-4$ units $\cdot \mathrm{h}^{-1}$ to obtain a systemic vascular resistance in the range of $800-1,200 \mathrm{dyn} \cdot \mathrm{s}^{-1} \cdot \mathrm{cm}^{-5}$.

\section{Endocrine management}

Sudden brain death induces a large release of catecholamines within $15 \mathrm{~min}$ (catecholamine storm) followed by a progressive decline. Vasopressin and cortisol commonly decrease after 15-45 min and can be undetectable $4 \mathrm{~h}$ after brain death. Thyroxine, triiodothyronine and insulin have also been shown to significantly decrease after several hours [16]. Hence, some groups have recommended hormonal substitution for brain-death donors [17, 18].

Hormonal substitution includes the administration of arginine vasopressin, methylprednisolone, insulin and triiodothyronine. The importance of vasopressin in haemodynamic and endocrine management of brain-dead donors has been mentioned previously and it should be used as the first choice after low-dose dopamine to maintain adequate blood pressure. FOLLETTE et al. [19] have shown that the administration of a bolus of methylprednisolone $\left(15 \mathrm{mg} \cdot \mathrm{kg}^{-1}\right)$ can prevent the deterioration of gas exchange and improve recovery of potential lung donors. The steroid bolus likely attenuates the inflammatory reaction and compensates for the deficit in hypophyseal hormones observed after brain death. A recent multivariate analysis on lung donor parameters has also demonstrated that the administration of corticosteroids to the donor was the most significant independent predictor of successful lung donation [20]. It should, therefore, be given to all donors after brain-death declaration. In contrast to vasopressin and methylprednisolone, the impact of thyroid hormones in the management of cadaveric donors has been more controversial. The administration of thyroid hormones, however, appears to be beneficial in haemodynamically unstable brain-dead donors [21-23], and a recent consensus on the management of donors for heart transplantation has recommended its use in donors with impaired cardiac function [8]. The Papworth programme in England has shown that aggressive haemodynamic and endocrine management can resuscitate up to $92 \%$ of heart donors previously deemed "unsuitable" for transplantation, leading to expansion of the heart donor pool by $30 \%$ [17].

\section{Fluid and electrolyte management}

Hypernatraemia secondary to diabetes insipidus is common and some studies have suggested that hypernatraemia is associated with increased risk of graft dysfunction after liver transplantation [24, 25]. Hence, the use of normal saline should be avoided. Dextrose solutions are preferred as they also help to maintain hepatic glucose stores. Colloid should be used to replace volume, and packed red cell transfusions to keep the haemoglobin above $10 \mathrm{~g} \cdot \mathrm{dL}^{-1}$. The goal is to achieve the lowest $\mathrm{CVP} / \mathrm{Ppcw}$ consistent with an adequate cardiac output and blood pressure. The electrolytes $\mathrm{K}^{+}, \mathrm{Mg}^{2+}$ and $\mathrm{Ca}^{2+}$ should also be replaced as required to keep these in the normal range.

\section{Pulmonary management}

Donors should be frequently (at least once an hour) turned and suctioned endobronchially. Bronchoscopy should be performed to remove mucous plugs. Sputum and bronchoalveolar lavage (BAL) specimens should be sent for Gram stain and culture. Early antibiotic therapy should be instituted and tailored to the results found on Gram stain and cultures, particularly in donors with infiltrates on the chest radiograph. A recruitment manoeuvre is recommended every $2 \mathrm{~h}$ to prevent atelectasis and to recruit alveoli, especially after the apnoea test. A fraction of inspired oxygen $\left(F \mathrm{I}, \mathrm{O}_{2}\right)$ of $\leqslant 50 \%$, positive end-expiratory pressure (PEEP) of 5-10 $\mathrm{cmH}_{2} \mathrm{O}$ and a tidal volume of $10 \mathrm{~mL} \cdot \mathrm{kg}^{-1}$ should be used to avoid ventilator-induced lung injury. Every $2-3 \mathrm{~h}$, oxygenation should be checked on an $F \mathrm{I}_{2} \mathrm{O}_{2}$ of $100 \%$ and PEEP of $5 \mathrm{cmH}_{2} \mathrm{O}$ to monitor the status of the lungs. A chest radiograph should also be done every $3-4 \mathrm{~h}$ to monitor the evolution of possible infiltrates.

\section{Other measures}

A series of additional measures are important to optimise the management of brain-dead multiorgan donors. These include the use of a warming blanket to prevent hypothermia, frequent turning and adequate pressure area care, regular nasogastric suction, eye care (corneas), and the use of strict aseptic technique.

\section{Methods of lung preservation}

The method of lung preservation has significantly improved over the past decade. Optimal techniques of flush delivery and lung preservation during the cold ischaemic time have been determined in animals and applied clinically [26]. A new preservation solution composed primarily of low potassium

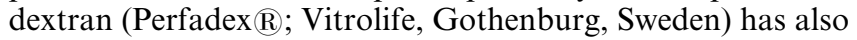
been developed specifically for the lung and has been implemented clinically by many centres over the past few years. Five clinical reports have compared the results of Perfadex $\mathbb{R}$ to those of Euro-Collins $\mathbb{R}$ ) (Baxter Healthcare Corp., Pharmacy Division, Deerfield, IL, USA) [27-31], and four of them observed significantly better lung function on arrival in the intensive care unit as well as a trend towards lower 30-day mortality and better 1-yr survival with Perfadex $\mathbb{R}$ (table 1). An additional report demonstrated that after adjustment for graft ischaemic time, extracellulartype preservation solutions were associated with a decreased incidence of primary graft failure after lung transplantation when compared with intracellular-type preservation solutions such as Euro-Collins $\AA$ [32].

Retrograde flush as well as low reperfusion pressure and protective ventilation have been shown to be important parameters in preserving lung function and in limiting the insult from ischaemia/reperfusion injury during LTx. 
Table 1. - Comparison between Perfadex $\AA$ (LPDG) and Euro-Collins $\AA$ (EC) in human lung transplantation

\begin{tabular}{|c|c|c|c|c|c|c|c|c|}
\hline \multirow[t]{2}{*}{ [Ref.] } & \multicolumn{2}{|c|}{ Patients $n$} & \multicolumn{3}{|c|}{ Lung function on arrival in ICU } & \multicolumn{3}{|c|}{ Mortality rate $\%$} \\
\hline & LPDG & $\mathrm{EC}$ & LPDG & $\mathrm{EC}$ & p-value & LPDG & $\mathrm{EC}$ & p-value \\
\hline [27] & 46 & 48 & $370 \pm 133^{\#}$ & $310 \pm 134^{\#}$ & 0.017 & $6.5^{\S}$ & $10.4^{\S}$ & 0.82 \\
\hline [28] & 57 & 63 & $34 \pm 11^{\oplus}$ & $30 \pm 10^{\bullet}$ & 0.04 & $8^{\S}$ & $14.2^{\S}$ & 0.35 \\
\hline [29] & 32 & 48 & $159 \pm 145^{+}$ & $242 \pm 265^{+}$ & 0.028 & $6^{\S}$ & $12^{\S}$ & 0.36 \\
\hline [30] & 50 & 50 & $234 \pm 20^{+}$ & $309 \pm 19^{+}$ & 0.001 & $7.7^{f}$ & $18.7^{f}$ & 0.01 \\
\hline
\end{tabular}

ICU: intensive care unit. ${ }^{\#}$ : arterial oxygen tension/inspiratory oxygen fraction; ${ }^{\circledR}$ : lung compliance $\mathrm{mL} \cdot \mathrm{mmHg}^{-1}$; ${ }^{+}$: alveolar arterial oxygen gradient; s: 30-day mortality rate; ${ }^{\prime}$ : 1-yr mortality rate.

Retrograde flush has been described for lung and heart-lung preservation and has been found to achieve better clearance of red blood cells, better distribution of the flush solution along the tracheobronchial tree, and better preservation of the surfactant function [33-36]. Several centres currently perform a retrograde flush after the anterograde flush [37, 38]. The retrograde flush can be performed in situ after the heart has been removed while the lungs are still ventilated, or later on the back table. In a group of 14 patients, VENUTA et al. [38] showed that the association of a retrograde flush to the anterograde flush can improve lung function after reperfusion of the transplanted lung.

The maintenance of low reperfusion pressure and protective ventilation during the initial period of reperfusion can limit lung damage by protecting the lung from high pulmonary artery pressures and elevated peak airway pressures [39, 40]. In practice, the blood flow is progressively reintroduced over a 10 -min period while the lung is ventilated with a protective ventilation strategy that includes low peak airway pressures (maximal of $20-25 \mathrm{cmH}_{2} \mathrm{O}$ ) and an $\mathrm{FI}, \mathrm{O}_{2}$ of $\leqslant 50 \%$ [41].

\section{Extension of lung donor selection criteria}

Improvement in donor management and refinements in the techniques of lung preservation have allowed progressive liberalisation of lung donor selection criteria without a significant impact on postoperative morbidity and mortality [42-45]. The parameters used to assess lungs from cadaveric donors are based on donor history, arterial blood gases, chest radiograph appearance, bronchoscopy findings, and physical examination of the lung at the time of retrieval [46]. The ideal parameters for lung donation are presented in table 2 .

In some series reported in the literature, the proportion of donors with extended criteria ranges $33-57 \%$ of the total number of lung donors (table 3 ). The main criteria that have been liberalised included aged $>55$ yrs, smoking history $>20$ pack-yrs, prolonged mechanical ventilation, and positive Gram stain on sputum or BAL samples. These criteria have been extended without significant adverse effects on the
Table 2. - Standard selection criteria for assessment of lung donor

Aged $<55$ yrs

Smoking history $<20$ pack-yrs

Clear chest radiograph

$\mathrm{Pa}, \mathrm{O}_{2}>39.9 \mathrm{kPa}$ on an $\mathrm{FI}, \mathrm{O}_{2}$ of $100 \%$ and PEEP of $5 \mathrm{cmH}_{2} \mathrm{O}$

No aspiration/sepsis

No significant chest trauma

Absence of purulent secretion at bronchoscopy

Absence of organism on Gram stain and cultures

Length of intubation $<48 \mathrm{~h}$

No previous cardiopulmonary surgery

$\mathrm{Pa}_{\mathrm{a}} \mathrm{O}_{2}$ : arterial oxygen tension; $\mathrm{FI}, \mathrm{O}_{2}$ : inspiratory oxygen fraction; PEEP: positive end-expiratory pressure.

postoperative outcome and are currently rarely given as a reason not to use the donor lungs [44, 47].

The presence of infiltrates, contusion, pneumothorax, or pleural effusion on the chest radiograph do not seem to affect the postoperative course after transplantation as long as it remains localised or improves with time $[42,44]$. However, the presence of persistent bilateral infiltrates on the chest radiograph can be associated with increased risk of postoperative death and should be considered as a contraindication for LTx [47]. The presence of persistent bilateral infiltrates has been associated with significantly higher levels of interleukin-8 (a potent chemokine for neutrophils) in the donor lung tissue, which may have been one of the reasons for the poor postoperative outcome that was observed with these lung donors [48].

Prolonged mechanical ventilation and the presence of organisms on sputum or BAL Gram stain does not appear to adversely influence the postoperative course as long as the donor and the recipient are covered with appropriate antibiotics and no signs of frank sepsis are present $[47,49,50]$. Copious purulent secretions or overt signs of aspiration at bronchoscopy have been found to be associated with significant postoperative complications and should remain a contraindication to the use of donor lungs for transplantation, regardless of the result of Gram stain [47].

Table 3.-Characteristics of extended donors used for lung transplantation reported in the literature

\begin{tabular}{|c|c|c|c|c|c|c|c|c|c|c|}
\hline \multirow[t]{2}{*}{ [Ref.] } & \multirow{2}{*}{$\begin{array}{c}\text { Transplants } \\
\mathrm{n}\end{array}$} & \multirow{2}{*}{$\begin{array}{l}\text { Extended } \\
\text { donors } \\
\text { used }\end{array}$} & \multicolumn{8}{|c|}{ Characteristics of extended donors } \\
\hline & & & $\begin{array}{c}\text { Aged } \\
>55 \text { yrs }\end{array}$ & $\begin{array}{c}\text { Smoking } \\
>20 \text { pack-yrs }\end{array}$ & $\begin{array}{c}\text { Inhaled } \\
\text { drugs }\end{array}$ & $\begin{array}{l}\text { Ventilation } \\
>5 \text { days }\end{array}$ & $\begin{array}{l}\text { Abnormal } \\
\text { CR }\end{array}$ & $\begin{aligned} & P \mathrm{a}, \mathrm{O}_{2} \\
< & 39.9 \mathrm{kPa}\end{aligned}$ & $\begin{array}{c}\text { Positive } \\
\text { Gram stain }\end{array}$ & $\begin{array}{c}\text { Copious } \\
\text { pus/aspiration }\end{array}$ \\
\hline [45] & 26 & $10(35)$ & NS & NS & NS & 0 & $6(60)$ & 0 & NS & $4(40)$ \\
\hline [42] & 133 & $44(33)$ & $2(5)$ & $9(20)$ & NS & NS & $34(77)$ & $6(14)$ & NS & 0 \\
\hline [44] & 140 & $64(57)$ & $4(6)$ & $5(8)$ & NS & NS & $39(61)$ & 0 & $24(38)$ & 0 \\
\hline [43] & 113 & $52(46)$ & $9(17)$ & $15(29)$ & $20(38)$ & $7(13)$ & $5(10)$ & 0 & NS & 0 \\
\hline [47] & 128 & $63(51)$ & $9(14)$ & $26(41)$ & NS & NS & $41(65)$ & 0 & NS & $8(13)$ \\
\hline
\end{tabular}

Data are presented as $\mathrm{n}(\%)$ unless otherwise stated. CR: chest radiograph; $\mathrm{Pa}, \mathrm{O}_{2}$ : arterial oxygen tension; NS: not significant. 
Oxygenation has been one criterion with which clinicians have rarely compromised. However, STRAZNICKA et al. [51] and GABBAY et al. [44] have shown that donors with poor initial oxygenation can be improved with aggressive management, and eventually used for LTx without significant impact on the postoperative course and 1-yr survival. Hence, donors with poor oxygenation should not be deemed unsuitable for transplantation, since up to $35 \%$ of them can be improved to reach an arterial oxygen tension $\left(\mathrm{Pa}, \mathrm{O}_{2}\right) / F \mathrm{I}, \mathrm{O}_{2}$ ratio of $>39.9 \mathrm{kPa}(300 \mathrm{mmHg})$ after aggressive resuscitation. The final $\mathrm{Pa}, \mathrm{O}_{2} / \mathrm{FI}, \mathrm{O}_{2}$ ratio performed in the operating room prior to lung retrieval should be the decisive number.

Recipient selection and expected length of ischaemic time are two important parameters to take into account when selecting a donor. Indeed, more flexibility can be used when choosing extended donors for recipients with low postoperative risk, such as emphysema or cystic fibrosis (CF) patients. Probably more restrictive donor selection criteria should be used for high-risk recipients such as those with primary pulmonary hypertension. Similarly, the length of ischaemic time should be considered in view of the overall quality of the donor. While the ischaemic time has occasionally been extended to $>12 \mathrm{~h}$ with excellent donors, without significant impact on postoperative outcome, the ischemic time is usually limited to $<8 \mathrm{~h}$ with extended lungs. It is recognised, however, that increased risk may be accepted when using lungs for recipients that are desperately ill and who are unlikely to be transplanted otherwise.

In summary, some factors remain important and should be considered to be contraindications to the use of lung donors. These factors include persistent bilateral infiltrates on chest radiograph, copious purulent secretions, or overt signs of aspiration at bronchoscopy. In contrast, other factors such as age, smoking history, positive Gram stain, number of days on the ventilator, or localised abnormality on the chest radiograph may not be associated with increased perioperative risk and should not by themselves preclude LTx. Lung oxygenation with a final $\mathrm{Pa}, \mathrm{O}_{2} / \mathrm{FI}, \mathrm{O}_{2}$ ratio of $>39.9 \mathrm{kPa}(300 \mathrm{mmHg})$ remains a respected factor in donor evaluation that is transgressed only occasionally. However, each donor should be considered individually and the risk that may be taken in choosing a donor should be weighed against the risk of the recipient dying on the waiting list.

\section{Living lobar transplantation}

Despite relaxation of standard donor criteria and utilisation of older and more marginal donors with increasing frequency, the number of cadaveric donor lungs has remained surprisingly low compared with the number of patients on the waiting list. The lack of suitable donors is even more acute in potential recipients with suppurative lung disease who require bilateral transplantation. This acute donor shortage led to the development of living lobar transplantation by STARNES et al. [52].

In living lobar transplantation, one donor provides a right lower lobe, the other donor a left lower lobe to a single bilateral lobar recipient. A number of programmes have developed a significant experience with this living lobar transplant strategy. The principal indication is CF [53]. However, patients with other conditions such as primary pulmonary hypertension, pulmonary fibrosis, and obliterative bronchiolitis have also undergone successful bilateral lobar transplantation [54-56].

STARNES et al. [53] have recently reported an impressive series of bilateral lobar transplantation in 123 patients. Perioperative morbidity and mortality as well as long-term functional outcome were similar to those reported for cadaveric donors by other groups and by the International Society for Heart and Lung Transplantation (ISHLT). Even more exciting is the superior survival that the paediatric recipients obtained in comparison with ISHLT data [1].

In living lobar transplantation, donor complications are a major concern. In the University of Southern California experience, overall significant morbidity was $4.6 \%$ [53]. There was no donor mortality. However, in an experience with 62 lobar donors, the Washington University group noted that 10 donors had 12 major complications requiring subsequent intervention, three of which resulted in permanent loss of function (phrenic nerve paralysis, loss of right middle lobe and bronchial stricture) [57]. There was no donor mortality in the Washington University experience.

\section{Nonheart-beating donor}

The concept of utilising lungs from donors whose circulation has ceased is not new. It is well known that lungs, inflated with oxygen, conserve their ability to oxygenate even after $1 \mathrm{~h}$ of in situ warm ischaemia following cessation of circulation $[58,59]$. In addition, it is recognised that topical cooling does provide some effective preservation and that this topical cooling can be conducted in situ in the nonheart-beating donor (NHBD) [60]. STEEN et al. [61] have reported a successful experience in which lungs were harvested from a NHBD. Since there was little information regarding the predeath pulmonary function in this donor, the donor lung was harvested, placed in an ex vivo ventilation/perfusion apparatus and its function judged acceptable. The lung was then transplanted and provided satisfactory function. Since that time, a number of centres have developed small experiences with NHBDs. In these initial cases, adequate information regarding lung function was available prior to circulatory arrest. The Washington University group has performed two such bilateral transplants with good results in both patients. There is a definite opportunity to increase the overall donor supply utilising this novel strategy.

\section{Split-lung technique}

The shortage of donor lungs suitable for children and small adults has led to the development of new operative techniques. Donor lungs can be downsized by peripheral nonanatomic segmental resections (tailoring) or by transplantation of cadaveric lobes in recipients with smaller thorax size [62]. CountIL and co-workers [63, 64] have developed a technique of bilateral LTx inspired from previous experience with bipartitioning of the liver. They split the left lung into two separate lobes. The left lower lobe is then used for left lung transplant and the left upper lobe for right lung transplant. The rotation of the left upper lobe into the right pleural space requires anastomosing the membranous portion of the bronchus to the cartilaginous ring on each of the donor and recipient side, but this did not cause any delay in healing. This technique allows bilateral LTx to be performed in a small-size recipient with excellent short- and long-term outcome [64, 65].

\section{Conclusion}

Over the last decade, aggressive donor management and refinements in the techniques of lung preservation have allowed gradual expansion of the lung donor selection 
criteria. Consequently, the proportion of lung donors used for transplantation has increased from $<10 \%$ to $\geqslant 40 \%$ of the donor pool [44, 47]. However, despite the significant increase in lung donors over the past several years, the number of patients on the waiting list still largely outnumber the donors available for lung transplantation. In the future, it is anticipated that the development of new strategies to repair and improve the quality of the lungs as well as the increasing use of nonheart-beating donors could have a tremendous impact on the number of transplants performed.

\section{References}

1. Hertz M, Taylor D, Trulock E, et al. The Registry of the International Society for Heart and Lung Transplantation: nineteenth official report - 2002. J Heart Lung Transplant 2002; 21: 950-970.

2. Fisher AJ, Dark JH, Corris PA. Improving donor lung evaluation: a new approach to increase organ supply for lung transplantation. Thorax 1998; 53: 818-820.

3. Lucas BA, Vaughn WK, Spees EK, Sanfilippo F. Identification of donor factors predisposing to high discard rates of cadaver kidneys and increased graft loss within one year posttransplantation - SEOPF 1977-1982. South-Eastern Organ Procurement Foundation. Transplantation 1987; 43: 253-258.

4. Busuttil RW, Goldstein LI, Danovitch GM, Ament ME, Memsic LD. Liver transplantation today. Ann Intern Med 1986; 104: 377-389.

5. Wicomb WN, Cooper DK, Lanza RP, Novitzky D, Isaacs S. The effects of brain death and 24 hours' storage by hypothermic perfusion on donor heart function in the pig. J Thorac Cardiovasc Surg 1986; 91: 896-909.

6. Pennefather SH, Bullock RE, Dark JH. The effect of fluid therapy on alveolar arterial oxygen gradient in brain-dead organ donors. Transplantation 1993; 56: 1418-1422.

7. Mertes PM, el Abassi K, Jaboin Y, et al. Changes in hemodynamic and metabolic parameters following induced brain death in the pig. Transplantation 1994; 58: 414 418.

8. Zaroff JG, Rosengard BR, Armstrong WF, et al. Maximizing use of organs recovered from the cadaver donor: cardiac recommendations. March 28-29, 2001, Crystal City, VA. $J$ Heart Lung Transplant 2002; 21: 1153-1160.

9. Ware LB, Fang X, Wang Y, Sakuma T, Hall TS, Matthay MA. Selected contribution: Mechanisms that may stimulate the resolution of alveolar edema in the transplanted human lung. J Appl Physiol 2002; 93: 1869-1874.

10. Katz K, Lawler J, Wax J, O'Connor R, Nadkarni V. Vasopressin pressor effects in critically ill children during evaluation for brain death and organ recovery. Resuscitation 2000; 47: 33-40.

11. Pennefather SH, Bullock RE, Mantle D, Dark JH. Use of low dose arginine vasopressin to support brain-dead organ donors. Transplantation 1995; 59: 58-62.

12. Iwai A, Sakano T, Uenishi M, Sugimoto H, Yoshioka T, Sugimoto T. Effects of vasopressin and catecholamines on the maintenance of circulatory stability in brain-dead patients. Transplantation 1989; 48: 613-617.

13. Chen JM, Cullinane S, Spanier TB, et al. Vasopressin deficiency and pressor hypersensitivity in hemodynamically unstable organ donors. Circulation 1999; 100: Suppl. 19, II244-II246.

14. Gramm HJ, Meinhold H, Bickel U, et al. Acute endocrine failure after brain death? Transplantation 1992; 54: 851-857.

15. Howlett TA, Keogh AM, Perry L, Touzel R, Rees LH. Anterior and posterior pituitary function in brain-stem-dead donors. A possible role for hormonal replacement therapy. Transplantation 1989; 47: 828-834.

16. Chen EP, Bittner HB, Kendall SW, van Trigt P. Hormonal and hemodynamic changes in a validated animal model of brain death. Crit Care Med 1996; 24: 1352-1359.

17. Wheeldon DR, Potter CD, Oduro A, Wallwork J, Large SR. Transforming the "unacceptable" donor: outcomes from the adoption of a standardized donor management technique. J Heart Lung Transplant 1995; 14: 734-742.

18. Cooper DK, Novitzky D, Wicomb WN. The pathophysiological effects of brain death on potential donor organs, with particular reference to the heart. Ann R Coll Surg Engl 1989; 71: 261-266.

19. Follette DM, Rudich SM, Babcock WD. Improved oxygenation and increased lung donor recovery with high-dose steroid administration after brain death. J Heart Lung Transplant 1998; 17: 423-429.

20. McElhinney DB, Khan JH, Babcock WD, Hall TS. Thoracic organ donor characteristics associated with successful lung procurement. Clin Transplant 2001; 15: 68-71.

21. Washida M, Okamoto R, Manaka D, et al. Beneficial effect of combined 3,5,3'-triiodothyronine and vasopressin administration of hepatic energy status and systemic hemodynamics after brain death. Transplantation 1992; 54 : $44-49$.

22. Salim A, Vassiliu P, Velmahos GC, et al. The role of thyroid hormone administration in potential organ donors. Arch Surg 2001; 136: 1377-1380.

23. Novitzky D, Cooper DK, Chaffin JS, Greer AE, DeBault LE, Zuhdi N. Improved cardiac allograft function following triiodothyronine therapy to both donor and recipient. Transplantation 1990; 49: 311-316.

24. Totsuka E, Dodson F, Urakami A, et al. Influence of high donor serum sodium levels on early postoperative graft function in human liver transplantation: effect of correction of donor hypernatremia. Liver Transpl Surg 1999; 5: 421428.

25. Markmann JF, Markmann JW, Markmann DA, et al. Preoperative factors associated with outcome and their impact on resource use in 1148 consecutive primary liver transplants. Transplantation 2001; 72: 1113-1122.

26. de Perrot M, Liu M, Waddell TK, Keshavjee S. Ischemiareperfusion induced lung injury. Am J Respir Crit Care Med 2003; 167: 490-511.

27. Fischer S, Matte-Martyn A, de Perrot M, et al. Lowpotassium dextran preservation solution improves lung function after human lung transplantation. $J$ Thorac Cardiovasc Surg 2001; 121: 594-596.

28. Struber M, Wilhelmi M, Harringer W, et al. Flush perfusion with low potassium dextran solution improves early graft function in clinical lung transplantation. Eur J Cardiothorac Surg 2001; 19: 190-194.

29. Muller C, Furst H, Reichenspurner H, Briegel J, Groh J, Reichart B. Lung procurement by low-potassium dextran and the effect on preservation injury. Munich Lung Transplant Group. Transplantation 1999; 68: 1139-1143.

30. Rega F, Verleden G, Vanhaecke J, Daenen W, Van Raemdonck D. Switch from Euro-Collins to Perfadex for pulmonary graft preservation resulted in superior outcome in transplant recipients. J Heart Lung Transplant 2003; 22: Suppl. 1, A117.

31. Aziz TM, Pillay TM, Corris PA, et al. Perfadex for clinical lung procurement: is it an advance? Ann Thorac Surg 2003; 75: 1960-1964.

32. Thabut G, Vinatier I, Brugiere $\mathrm{O}$, et al. Influence of preservation solution on early graft failure in clinical lung transplantation. Am J Respir Crit Care Med 2001; 164: 12041208.

33. Baretti R, Bitu-Moreno J, Beyersdorf F, Matheis G, Francischetti I, Kreitmayr B. Distribution of lung preservation solutions in parenchyma and airways: influence of atelectasis and route of delivery. $J$ Heart Lung Transplant 1995; 14: 80-91.

34. Chen CZ, Gallagher RC, Ardery P, Dyckman W, Low HB. Retrograde versus antegrade flush in canine left lung 
preservation for six hours. J Heart Lung Transplant 1996; 15: 395-403.

35. Varela A, Montero CG, Cordoba $\mathrm{M}$, et al. Improved distribution of pulmonary flush solution to the tracheobronchial wall in pulmonary transplantation. Eur Surg Res 1997; 29: $1-4$.

36. Wittwer T, Fehrenbach A, Meyer D, et al. Retrograde flush perfusion with low-potassium solutions for improvement of experimental pulmonary preservation. J Heart Lung Transplant 2000; 19: 976-983.

37. Varela A, Cordoba M, Serrano-Fiz S, et al. Early lung allograft function after retrograde and antegrade preservation. J Thorac Cardiovasc Surg 1997; 114: 1119-1120.

38. Venuta F, Rendina EA, Bufi M, et al. Preimplantation retrograde pneumoplegia in clinical lung transplantation. J Thorac Cardiovasc Surg 1999; 118: 107-114.

39. Pierre AF, DeCampos KN, Liu M, et al. Rapid reperfusion causes stress failure in ischemic rat lungs. $J$ Thorac Cardiovasc Surg 1998; 116: 932-942.

40. de Perrot M, Imai Y, Volgyesi GA, et al. Effect of ventilatorinduced lung injury on the development of reperfusion injury in a rat lung transplant model. $J$ Thorac Cardiovasc Surg 2002; 124: 1137-1144.

41. McRae KM. Pulmonary transplantation. Curr Opin Anesthesiol 2000; 13: 53-59.

42. Sundaresan S, Semenkovich J, Ochoa L, et al. Successful outcome of lung transplantation is not compromised by the use of marginal donor lungs. J Thorac Cardiovasc Surg 1995; 109: 1075-1079.

43. Bhorade SM, Vigneswaran W, McCabe MA, Garrity ER Liberalization of donor criteria may expand the donor pool without adverse consequence in lung transplantation. $J$ Heart Lung Transplant 2000; 19: 1199-1204.

44. Gabbay E, Williams TJ, Griffiths AP, et al. Maximizing the utilization of donor organs offered for lung transplantation. Am J Respir Crit Care Med 1999; 160: 265-271.

45. Kron IL, Tribble CG, Kern JA, et al. Successful transplantation of marginally acceptable thoracic organs. Ann Surg 1993; 217: 518-522.

46. Sundaresan S, Trachiotis GD, Aoe M, Patterson GA, Cooper JD. Donor lung procurement: assessment and operative technique. Ann Thorac Surg 1993; 56: 1409-1413.

47. Pierre AF, Sekine Y, Hutcheon MA, Waddell TK, Keshavjee SH. Marginal donor lungs: A reassessment. $J$ Thorac Cardiovasc Surg 2002; 123: 421-428.

48. de Perrot M, Sekine Y, Fischer S, et al. Interleukin-8 release during early reperfusion predicts graft function in human lung transplantation. Am J Respir Crit Care Med 2002; 165: 211-215.

49. Weill D, Dey GC, Hicks RA, et al. A positive donor gram stain does not predict outcome following lung transplantation. J Heart Lung Transplant 2002; 21: 555-558.

50. Dowling RD, Zenati M, Yousem SA, et al. Donortransmitted pneumonia in experimental lung allografts.
Successful prevention with donor antibiotic therapy. J Thorac Cardiovasc Surg 1992; 103: 767-772.

51. Straznicka M, Follette DM, Eisner MD, Roberts PF, Menza RL, Babcock WD. Aggressive management of lung donors classified as unacceptable: excellent recipient survival one year after transplantation. $J$ Thorac Cardiovasc Surg 2002; 124: 250-258.

52. Starnes VA, Barr ML, Cohen RG, et al. Living donor lobar lung transplantation experience: Intermediate results. J Thorac Cardiovasc Surg 1996; 112: 1284-1290.

53. Starnes VA, Barr ML, Woo M. A decade of living lobar transplantation: Recipient outcomes. J Thorac Cardiovasc Surg 2004; (in press)

54. Starnes VA, Barr ML, Schenkel FA, et al. Experience with living donor lobar transplantation for indications other than cystic fibrosis. J Thorac Cardiovasc Surg 1997; 114: 917-921.

55. Date H, Nagahiro I, Aoe M, et al. Living donor lobar lung transplantation for primary pulmonary hypertension in an adult. J Thorac Cardiovasc Surg 2001; 122: 817-818.

56. Date $\mathrm{H}$, Sano Y, Aoe M, et al. Living donor lobar lung transplantation for bronchiolitis obliterans after Stephens Johnson syndrome. J Thorac Cardiovasc Surg 2002; 123 389-391.

57. Battafarano RJ, Anderson RC, Meyers BF, et al. Perioperative complications after living donor lobectomy. J Thorac Cardiovasc Surg 2000; 120: 909-915.

58. Egan TM, Lambert CJ, Reddick R, Ulicny KS Jr, Keagy BA, Wilcox BR. A strategy to increase the donor pool: Use of cadaver lungs for transplantation. Ann Thorac Surg 1991; 52: $1113-1121$.

59. Van Raemdonck DEM, Jannis NCP, De Leyn PRJ, Flameng WJ, Lerut TE. Warm ischemic tolerance in collapsed pulmonary grafts is limited to one hour. Ann Surg 1998; 228: 788-796.

60. Steen S, Sjoberg T, Ingemansson R, Lindberg L. Efficacy of topical cooling in lung preservation: Is a reappraisal due? Ann Thorac Surg 1994; 58: 1657-1663.

61. Steen S, Sjoberg T, Pierre L, Liao Q, Eriksson L, Algotsson L. Transplantation of lungs from a non-heart beating donor Lancet 2001; 357: 825-829.

62. Wisser W, Klepetko W, Wekerle T, et al. Tailoring of the lung to overcome size disparities in lung transplantation. J Heart Lung Transplant 1996; 15: 239-242.

63. Couetil JP, Grousset A, Tolan MJ, Benaim A, Fayolle P, Carpentier A. Experimental bilateral lobar lung transplantation and its application in the human. Thorax 1997; 52: 714 717 .

64. Couetil JP, Tolan MJ, Loulmet DF, et al. Pulmonary bipartitioning and lobar transplantation: a new approach to donor organ shortage. J Thorac Cardiovasc Surg 1997; 113: 529-537.

65. Artemiou $\mathrm{O}$, Birsan $\mathrm{T}$, Taghavi $\mathrm{S}$, et al. Bilateral lobar transplantation with the split lung technique. $J$ Thorac Cardiovasc Surg 1999; 118: 369-370. 